\title{
Investigation of a mesospheric bore event over northern China
}

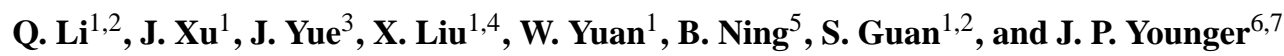 \\ ${ }^{1}$ State Key Laboratory of Space Weather, Center for Space Science and Applied Research, Chinese Academy of Sciences, \\ Beijing 100190, China \\ ${ }^{2}$ University of Chinese Academy of Sciences, Beijing 100049, China \\ ${ }^{3}$ Hampton University, Hampton, VA, USA \\ ${ }^{4}$ College of Mathematics and Information Science, Henan Normal University, Xinxiang, China \\ ${ }^{5}$ Beijing National Observatory of Space Environment, Institute of Geology and Geophysics, Chinese Academy of Sciences, \\ Beijing, China \\ ${ }^{6}$ School of Chemistry and Physics, University of Adelaide, Adelaide, South Australia, Australia \\ ${ }^{7}$ ATRAD Pty Ltd., Thebarton, South Australia, Australia
}

Correspondence to: Q. Li (qzli@spaceweather.ac.cn)

Received: 14 September 2012 - Revised: 1 February 2013 - Accepted: 2 February 2013 - Published: 5 March 2013

\begin{abstract}
A mesospheric bore event was observed using an $\mathrm{OH}$ all-sky airglow imager (ASAI) at Xinglong $\left(40.2^{\circ} \mathrm{N}\right.$, $117.4^{\circ} \mathrm{E}$ ), in northern China, on the night of 8-9 January 2011. Simultaneous observations by a Doppler meteor radar, a broadband sodium lidar, and TIMED/SABER OH intensity and temperature measurements are used to investigate the characteristics and environment of the bore propagation and the possible relations with the Na density perturbations. The bore propagated from northeast to southwest and divided the sky into bright and dark halves. The calculations show that the bore has an average phase velocity of $68 \mathrm{~m} \mathrm{~s}^{-1}$. The crests following the bore have a horizontal wavelength of $\sim 22 \mathrm{~km}$. These parameters are consistent with the hydraulic jump theory proposed by Dewan and Picard, as well as the previous bore reports. Simultaneous wind measurements from the Doppler meteor radar at Shisanling $\left(40.3^{\circ} \mathrm{N}, 116.2^{\circ} \mathrm{E}\right)$ and temperature data from SABER on board the TIMED satellite are used to characterize the propagating environment of the bore. The result shows that a thermal-Doppler duct exists near the $\mathrm{OH}$ layer that supports the horizontal propagation of the bore. Simultaneous Na lidar observations at Yanqing $\left(40.4^{\circ} \mathrm{N}, 116.0^{\circ} \mathrm{E}\right)$ suggest that there is a downward displacement of $\mathrm{Na}$ density during the passage of the mesospheric bore event.
\end{abstract}

Keywords. Atmospheric composition and structure (Airglow and aurora) - Meteorology and atmospheric dynamics (Middle atmosphere dynamics; Waves and tides)

\section{Introduction}

The mesospheric bore is an interesting atmospheric wave phenomenon that has been observed in the mesosphere and lower thermosphere (MLT) region. During the ALOHA-93 campaign, using an airglow imager, Taylor et al. (1995) reported a spectacular frontal event, which divided the sky into bright and dark areas. Dewan and Picard (1998) first interpreted this phenomenon as a mesospheric bore using the hydraulic jump theory (Lighthill, 1978), similar to the tropospheric bore. They suggested that the mesospheric bore might be associated with a mesospheric temperature inversion layer that forms a wave duct favorable to the propagation of a bore. Dewan and Picard (2001) proposed that the interaction between gravity waves and the mean flow in a critical layer could play an important role in the formation of a mesospheric bore. Using a numerical model, Seyler (2005) investigated the nonlinear development and evolution of mesospheric bores trapped within thermal inversion layers. Laughman et al. (2009) presented a further discussion on the formation of mesospheric bores in different ducting environments, including thermal ducts, Doppler ducts and combinations of thermal and Doppler ducts.

Mesospheric bore events have been extensively reported in the literature (e.g., Brown et al., 2004; Fechine et al., 2009; Nielsen et al., 2006; Narayanan et al., 2009; She et al., 2004; Smith et al., 2003, 2005, 2006; Stockwell et al., 2006, 2011; Yue et al., 2009). These observations showed 


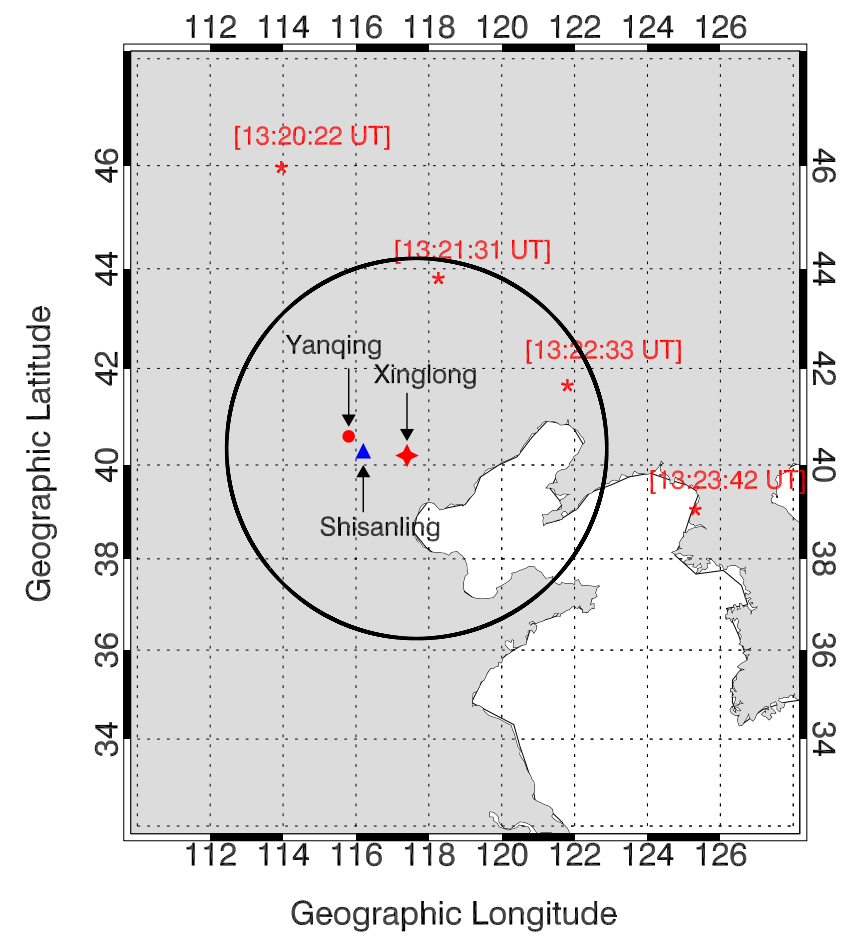

Fig. 1. Map showing the locations of the all-sky airglow imager at Xinglong (red star), the meteor radar at Shisanling (blue triangle) and the Na lidar at Yanqing (red dot). The circle has a radius of $400 \mathrm{~km}$, which corresponds to the $\sim 158^{\circ}$ field of view at a height of $87 \mathrm{~km}$. The sounding footprints of the TIMED/SABER measurements are denoted by red asterisks.

that the environments favoring the formation of mesospheric bores are temperature inversion layers (Smith et al., 2003; She et al., 2004) and Doppler wind ducts (Fechine et al., 2009). There are recent observations of Thermal and thermalDoppler ducts in the $\mathrm{OH}$ airglow layer (Bageston et al., 2011a, b; Stockwell et al., 2011). Smith et al. (2005) and Yue et al. (2009) investigated the formation of mesospheric bores from large-scale mesospheric gravity waves. It is known that jet-front systems in the troposphere are important sources of gravity waves (Zhang, 2004). Jet-front systems are suggested to be highly correlated to mesospheric bore events (Smith et al., 2003; Brown et al., 2004; Yue et al., 2009).

In this work, we report on a mesospheric bore event observed on the night of 8-9 January 2011, by an $\mathrm{OH}$ allsky airglow imager (ASAI) located at Xinglong $\left(40.2^{\circ} \mathrm{N}\right.$, $117.4^{\circ} \mathrm{E}$ ), China (Li et al., 2011). To our knowledge, this is the first reported mesospheric bore observation over China. In addition, simultaneous wind data obtained from an ATRAD MDR6 all-sky VHF meteor radar at Shisanling $\left(40.3^{\circ} \mathrm{N}, 116.2^{\circ} \mathrm{E}\right)$ and Version 1.07 (V1.07) temperature data from the SABER instrument on board the TIMED satellite were used to investigate the environment in which the bore propagated and the propagation characteristics of the bore. Furthermore, a simultaneous Na lidar density measure- ment at Yanqing $\left(40.4^{\circ} \mathrm{N}, 116.0^{\circ} \mathrm{E}\right)$ is used to explore possible disturbances to $\mathrm{Na}$ density due to the bore.

\section{Observations}

Figure 1 shows a map giving the locations of Xinglong $\left(40.2^{\circ} \mathrm{N}, 117.4^{\circ} \mathrm{E}\right)$ (red star), Shisanling $\left(40.3^{\circ} \mathrm{N}\right.$, $\left.116.2^{\circ} \mathrm{E}\right)$ (blue triangle) and Yanqing $\left(40.4^{\circ} \mathrm{N}, 116.0^{\circ} \mathrm{E}\right)$ (red dot), where the Meridian Project All-Sky Airglow Imaging (ASAI) system, the meteor radar and Na lidar are in operation, respectively. The Meridian Project ASAI system consists of a high resolution, $1024 \times 1024$ pixel back-illuminated CCD detector with a pixel depth of 16 bits. The imager contains an eight-position filter wheel. The $\mathrm{OH}$ near infrared (NIR) band filter $(715-930 \mathrm{~nm})$ has a notch centered at $865.5 \mathrm{~nm}$ to block the $\mathrm{O}_{2}(0,1)$ emission. In this study, only the OH NIR band airglow emission was recorded. A detailed description of the imager is given by Li et al. (2011). The exposure time of each $\mathrm{OH}$ image is $1 \mathrm{~min}$, recorded at an interval of $1 \mathrm{~min}$.

Along with the ASAI observation, simultaneous wind data are obtained from the meteor radar at Shisanling $\left(40.3^{\circ} \mathrm{N}\right.$, $116.2^{\circ} \mathrm{E}$ ), which is about $100 \mathrm{~km}$ west of the ASAI's site. The radar operates at a frequency of $38.9 \mathrm{MHz}$, with a $7.5 \mathrm{~kW}$ transmit power and a pulse repetition frequency of the radar is $430 \mathrm{~Hz}$ (Holdsworth et al., 2004). The radar measures wind velocities in the MLT at altitudes from 70 to $110 \mathrm{~km}$ with an integration time of $1 \mathrm{~h}$ and a height interval of $2 \mathrm{~km}$, respectively. The wind data used here are interpolated at 1$\mathrm{km}$ height interval. The temperature data are obtained from the TIMED/SABER instrument. Details of how to derive kinetic temperatures from $\mathrm{CO}_{2}$ emissions are outlined by Mertens et al. (2001). The red asterisks in Fig. 1 denote the TIMED/SABER descending footprints on the night of 8-9 January 2011. Simultaneous Na density is measured by the $\mathrm{Na}$ lidar at Yanqing $\left(40.4^{\circ} \mathrm{N}, 116.0^{\circ} \mathrm{E}\right)$, which is about $120 \mathrm{~km}$ west of the ASAI. The Meridian Project dualwavelength sodium fluorescence lidar system consists of two high-power pulsed lasers (at $589 \mathrm{~nm}$ and $532 \mathrm{~nm}$ ), with output energies of $40 \mathrm{~mJ}$ and $500 \mathrm{~mJ}$, respectively. A large aperture telescope (1-m diameter) and high sensitivity photomultipliers (PMTs) are used to detect the weak backscattered signal. The time resolution of the Na lidar is $3 \mathrm{~min}$, with a vertical resolution of $96 \mathrm{~m}$. A more detailed description of the lidar system is given by Wang et al. (2012).

\section{Results}

\subsection{The mesospheric bore event}

The mesospheric bore event was observed with the allsky airglow imager on the night of 8-9 January 2011, at Xinglong $\left(40.2^{\circ} \mathrm{N}, 117.4^{\circ} \mathrm{E}\right)$, in northern China. The bore first appeared on the northeast (NE) horizon at 18:52 UT 


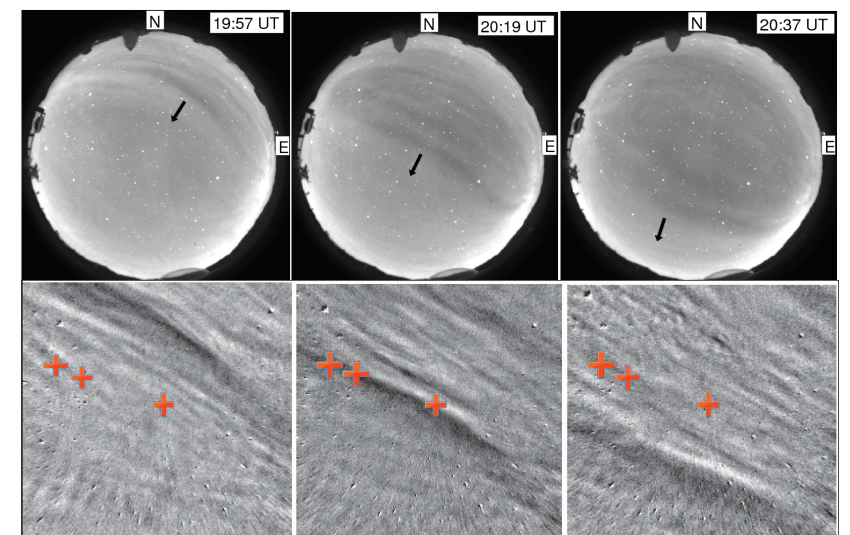

Fig. 2. All-sky OH images showing the mesospheric bore event observed on the night of 8-9 January 2011 at 19:57 UT, 20:19 UT and 20:37 UT. The top panels show the raw images. The propagation direction of the bore is denoted by the arrow. The bottom panels show the unwrapped time difference images corresponding to the top panels. The time difference images in the lower panels are created by taking the difference between two adjacent images. The time interval between each recorded $\mathrm{OH}$ image is $1 \mathrm{~min}$. The scale of the bottom panel is $300 \mathrm{~km} \times 300 \mathrm{~km}$. The red crosses in each panel from right to left indicate the locations of the all-sky airglow imager, the meteor radar and the $\mathrm{Na}$ lidar.

$(\mathrm{LT}=\mathrm{UT}+8 \mathrm{~h})$ and propagated towards the southwest $(\mathrm{SW})$. Figure 2 shows three airglow images of the bore event observed in the $\mathrm{OH}$ emissions at 19:57 UT, 20:19 UT and 20:37 UT. In the top panels of Fig. 2, we can see a clear line at the bore front dividing the sky into bright and dark areas. The arrows over each image indicate the propagation direction of the bore. To see the bore event more clearly, the time difference images projected onto the geographic coordinates corresponding to the top panels are shown in the bottom panels of Fig. 2. The leading front of the bore extended more than $300 \mathrm{~km}$ and it passed the zenith of the ASAI at 20:19 UT. Four to five crests behind the leading front of the bore can be seen at this time (the bottom panels of Fig. 2). From 19:30 UT to 20:30 UT, the horizontal phase speed of the bore increased from $62 \mathrm{~m} \mathrm{~s}^{-1}$ to $74 \mathrm{~m} \mathrm{~s}^{-1}$ (the average value was about $68 \mathrm{~m} \mathrm{~s}^{-1}$ ). After 20:30 UT, the first and second crests behind the leading front became obscured and almost disappeared at 20:37 UT. At least three wave crests can still be recognized at 20:37 UT (the bottom panels of Fig. 2). The horizontal wavelength of the bore crest does not show distinct variation as the bore propagated and is $\sim 22 \mathrm{~km}$. As time passed, the leading front became unstable and broke. The leading front of the bore disappeared at about 21:22 UT. Though they were not very clear, several wave crests still can be seen inside the field-of-view until the end of the observation at 21:39 UT. Figure 3 displays sequential crosssections of emission intensity perpendicular to the bore front derived from raw unwrapped $\mathrm{OH}$ images, which shows a clear step function. The $\mathrm{OH}$ emission intensity decreased by

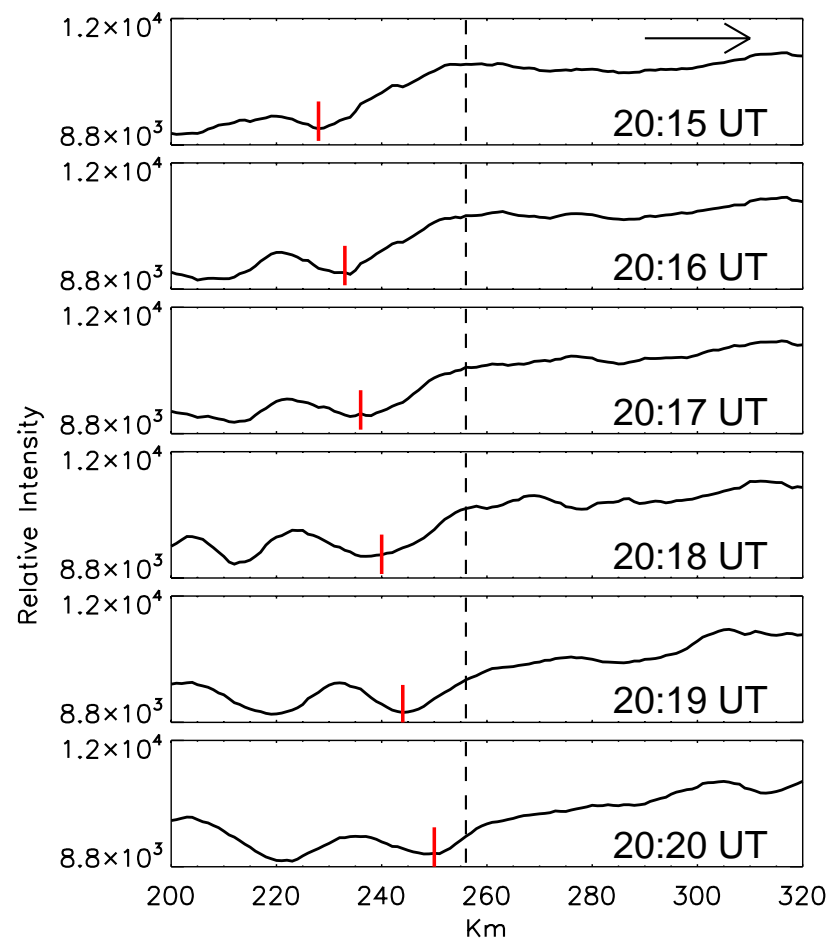

Fig. 3. Relative $\mathrm{OH}$ emission intensity variation perpendicular to the bore front (extracted from raw unwrapped $\mathrm{OH}$ images). The bore movement direction is shown by the arrow. The vertical dashed line marks the position of zenith. The vertical red line in each profile indicates the position of the leading emission minimum of the bore. The relative intensity represents the counts per pixel from raw images.

$\sim 14 \%$ behind the bore front at around 20:19 UT. The propagation direction of the bore displays obvious rotation, moving (clockwise from north) from $204^{\circ}$ to $184^{\circ}$ during the bore event. We use an average direction of bore propagation in the analysis of Sect. 3.2.

According to the Dewan and Picard (1998) model, Medeiros et al. (2005) explained that the $\mathrm{OH}$ emission is pushed upward by a bore trapped in a duct. The density of molecular hydroxyl decreases, resulting in a decrease in emission. Bageston et al. (2011b) also found a similar structure showing a decrease behind a "wall" front. When only the $\mathrm{OH}$ emission observation is available, we are not able to discuss the complementary bore effect among different airglow layers. In contrast, bores with increased emission intensity behind the leading front have been reported by other observations (Taylor et al., 1995; Narayanan et al., 2009; Nielsen et al., 2006; Stockwell et al., 2006, 2011; Fechine et al., 2009). In a recent paper, Bageston et al. (2011a) reported a clear wave front followed by a series of wave crests. However, a clear step function was not observed. 


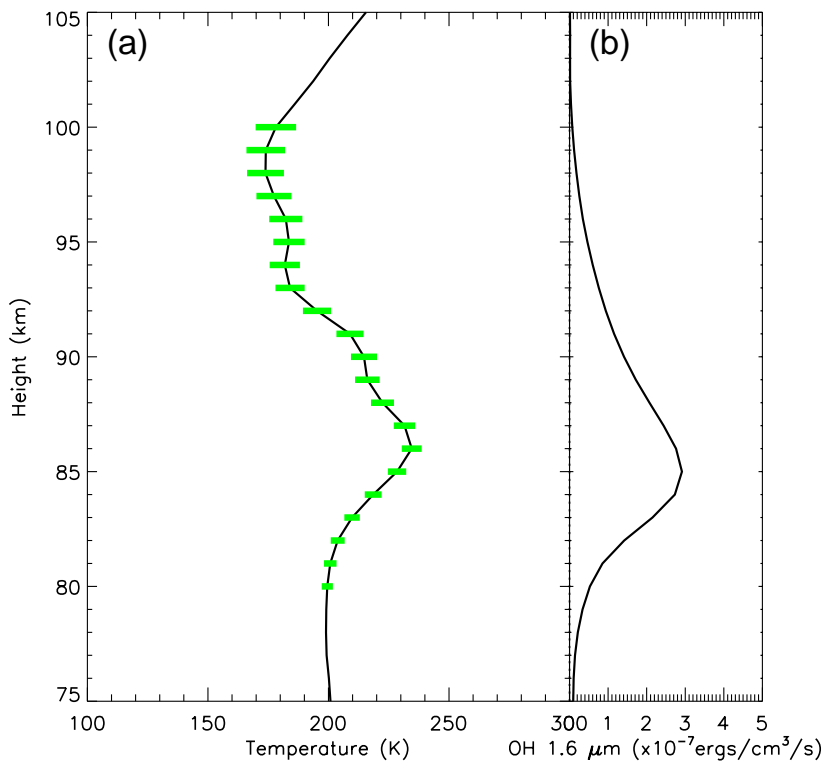

Fig. 4. Average height profiles of (a) temperature and (b) $\mathrm{OH}$ $1.6 \mu \mathrm{m}$ emission intensity obtained by the TIMED/SABER at 13:20 UT, 13:21 UT, 13:22 UT, and 13:23 UT on the night of 89 January 2011. The green bars give the RSS uncertainty.

\subsection{Propagation environment of the bore event}

Simultaneous horizontal wind data from the meteor radar at Shisanling $\left(40.3^{\circ} \mathrm{N}, 116.2^{\circ} \mathrm{E}\right)$ was used to investigate the background state during the bore event, with temperatures obtained from TIMED/SABER measurements. Previous studies have shown that a thermal and/or a Doppler duct formed by a temperature inversion layer and/or a large wind shear may play important roles in the formation and propagation of mesospheric bores (Dewan and Picard, 1998, 2001; Fechine et al., 2009; Bageston et al., 2011b). Several mesospheric bore events have been reported to be associated with temperature inversion layers (e.g., Smith et al., 2003, 2005; She et al., 2004; Yue et al., 2009). Figure 4 shows the average profile of the V1.07 temperature and the $1.6 \mu \mathrm{m} \mathrm{OH}$ emission intensity measured by TIMED/SABER on the night of 8-9 January 2011 around 13:20 UT, about $6 \mathrm{~h}$ prior to the bore event. A temperature inversion layer can be seen in the height range of $80-86 \mathrm{~km}$ (Fig. 4a). The $1.6 \mu \mathrm{m} \mathrm{OH}$ emission intensity profile (Fig. 4b) shows that the peak of $\mathrm{OH}$ emission altitude is at $85 \mathrm{~km}$. The square of the Brunt-Väisälä frequency $N^{2}$ is expressed as

$N^{2}=\frac{g}{T}\left(\frac{\mathrm{d} T}{\mathrm{~d} z}+\frac{g}{c_{p}}\right)$

where $g=9.54 \mathrm{~m} \mathrm{~s}^{-2}, \quad T$ is the temperature, $c_{p}=$ $1005 \mathrm{~J} \mathrm{~kg}^{-1} \mathrm{~K}^{-1}$ is the specific heat at constant pressure, and $\mathrm{d} T / \mathrm{d} z$ is the vertical gradient of temperature from the TIMED/SABER observations near the ASAI. Using Eq. (1), the square of the Brunt-Väisälä frequency

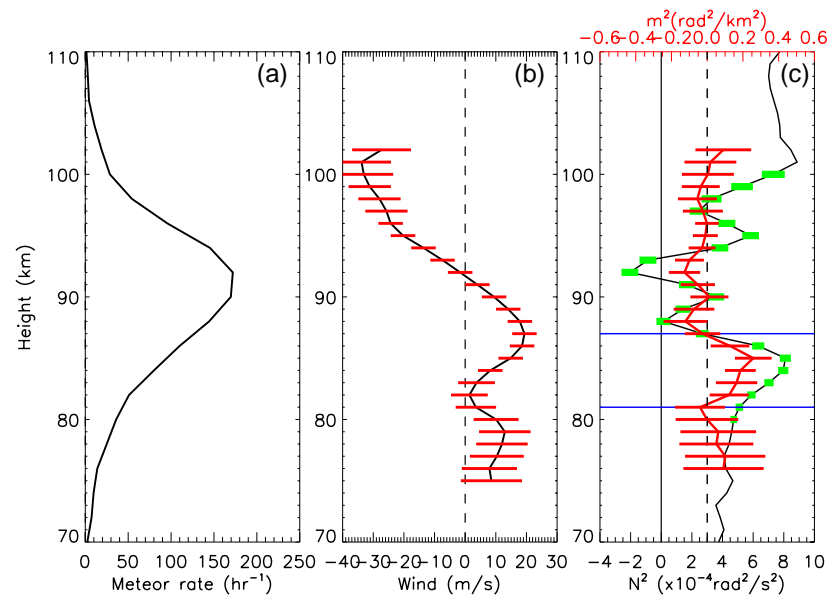

Fig. 5. (a) The averaged meteor radar detection rate from 19:00 UT to 21:00 UT. (b) The averaged meteor radar wind profile in the wave propagation direction from 19:00 UT to 21:00 UT. (c) Height profile of the square of the Brunt-Väisälä frequency $N^{2}$ (black solid line) and vertical wavenumber $m^{2}$ (red solid line) derived from the temperature profile in Fig. 4a and the average meteor radar wind profile in panel (b). The solid blue lines give the top and bottom boundaries of the duct region where the $m^{2}$ is positive, above and below which $m^{2}$ is negative. Errors bars show one standard deviation.

$N^{2}$ derived from the V1.07 SABER temperature profile in Fig. 4a is shown in Fig. 5c (the black solid line). We can see that there is a thermal duct between 80 and $87 \mathrm{~km}$. There is no uncertainty specified for each individual SABER temperature profile. Nevertheless, Remsberg et al. (2008) provided estimations of random and systematic errors for temperature in the Non-Local Thermodynamic Equilibrium (non-LTE) regime of the SABER measurements from 80 to $100 \mathrm{~km}$ at mid-latitude (Table 2 in Remsberg et al., 2008). Further details of the non-LTE temperature algorithm are in Garcia-Comas et al. (2008). The root-sum-square (RSS) uncertainties of temperature (Table 2 in Remsberg et al., 2008) are presented in Fig. 4a (green bar). The corresponding uncertainties of $N^{2}$ are shown in Fig. 5c (green bar). It is noted that the RSS uncertainties of temperature have little influence on the overall $N^{2}$ profile. Because the SABER temperature profile was measured $6 \mathrm{~h}$ prior to the bore and no other simultaneous temperature measurement is available, we have to use the SABER data with caution in this paper.

In order to investigate the vertical propagation condition of the bore event, we calculate the vertical wavenumber using the gravity wave dispersion relation (Chimonas and Hines, 1986; Isler et al., 1997)

$m^{2}=\frac{N^{2}}{(c-u)^{2}}+\frac{u_{z z}}{c-u}-k^{2}$,

where $k$ is the horizontal wavenumber, $c$ is the phase velocity of the wave, $u$ is the wind velocity in the wave direction measured by the meteor radar, and $u_{z z}$ is the second derivative of 
$u$ with height $z$. The height profile of the square of the vertical wavenumber $m^{2}$ derived from the wind profile (Fig. 5b) and the $N^{2}$ profile (black solid line in Fig. 5c) is shown in Fig. $5 \mathrm{c}$ (red solid line). If $m^{2}>0$, the wave can freely propagate. If $m^{2}<0$, the wave is evanescent. If there is a region of $m^{2}>0$ surrounded by regions of $m^{2}<0$ above and below, the gravity wave can be trapped and ducted since the waves can be reflected from both the top and bottom boundaries of the duct region. Figure $5 \mathrm{c}$ shows that there is a duct region in the height range of $81-87 \mathrm{~km}$ (between the blue lines). The duct is a necessary condition for the formation and propagation of mesospheric bores (Dewan and Picard, 1998). Using a Monte-Carlo simulation, Vincent et al. (2010) attained the uncertainty in each wind component (zonal and meridional wind) as a function of meteor count rate. Due to the use of similar radar systems, we use the meteor count rate to estimate the measurement uncertainty (see the 1 and 2 columns of Table 1 in Vincent et al., 2010) and then propagate the uncertainty to the $m^{2}$ profile. Figure 5a presents the averaged meteor count rate between 19:00 UT and 21:00 UT in the height range of $70-110 \mathrm{~km}$. It shows the meteor count rate varies with height with a peak at $92 \mathrm{~km}$. The uncertainties of the horizontal wind in the direction of bore propagation are denoted by the error bars in Fig. 5b. The uncertainty decreases with increasing height below $92 \mathrm{~km}$ and increases with height above $92 \mathrm{~km}$. The uncertainty of wind at $81 \mathrm{~km}$ and $87 \mathrm{~km}$ are $\pm 7 \mathrm{~m} \mathrm{~s}^{-1}$ and $\pm 5 \mathrm{~m} \mathrm{~s}^{-1}$, respectively. The standard deviations of the $m^{2}$ induced by the uncertainties of the horizontal wind are indicated by the error bars in Fig. 5c (red bars). The uncertainty at bottom boundary of the duct is larger than at top boundary of the duct (see Fig. 5c).

The hourly zonal and meridional winds measured by the meteor radar on the night of 8-9 January 2011 are displayed in Fig. 6a and b, respectively. The vertical solid lines indicate the time when the bore was observed. Figure 6 shows a strong semidiurnal tide, which is a common feature in winter at northern mid-latitudes (Yue et al., 2010). Using the 4station meteor radar chain dataset along the $120^{\circ} \mathrm{E}$ meridian in the Northern Hemisphere in December 2011, Yu et al. (2013) found that the semidiurnal tide dominates at northern mid-latitudes in the height range of $80-100 \mathrm{~km}$ with a peak around $96 \mathrm{~km}$. Fechine et al. (2009) reported a mesospheric bore propagating in a Doppler wind duct that was associated with a semidiurnal tidal oscillation in the meteor radar wind. Bageston et al. (2011a) reported a mesospheric front supported by a thermal-Doppler duct.

In this work, we consider the peak $\mathrm{OH}$ emission located at $85 \mathrm{~km}$ (see Fig. 4b). It is noted that a strong wind shear from $80 \mathrm{~km}$ to $90 \mathrm{~km}$ is present in the zonal direction when the bore was observed (Fig. 6a). Figure $6 \mathrm{c}$ depicts the horizontal wind in the bore propagation direction. During the passage of the bore (the time indicated by the vertical solid lines in Fig. 6c), the background wind in the bore propagation direction decreased from $30 \mathrm{~m} \mathrm{~s}^{-1}$ to $-10 \mathrm{~m} \mathrm{~s}^{-1}$ at the height of $\sim 85 \mathrm{~km}$. The wind in the wave propagation direction exhib-
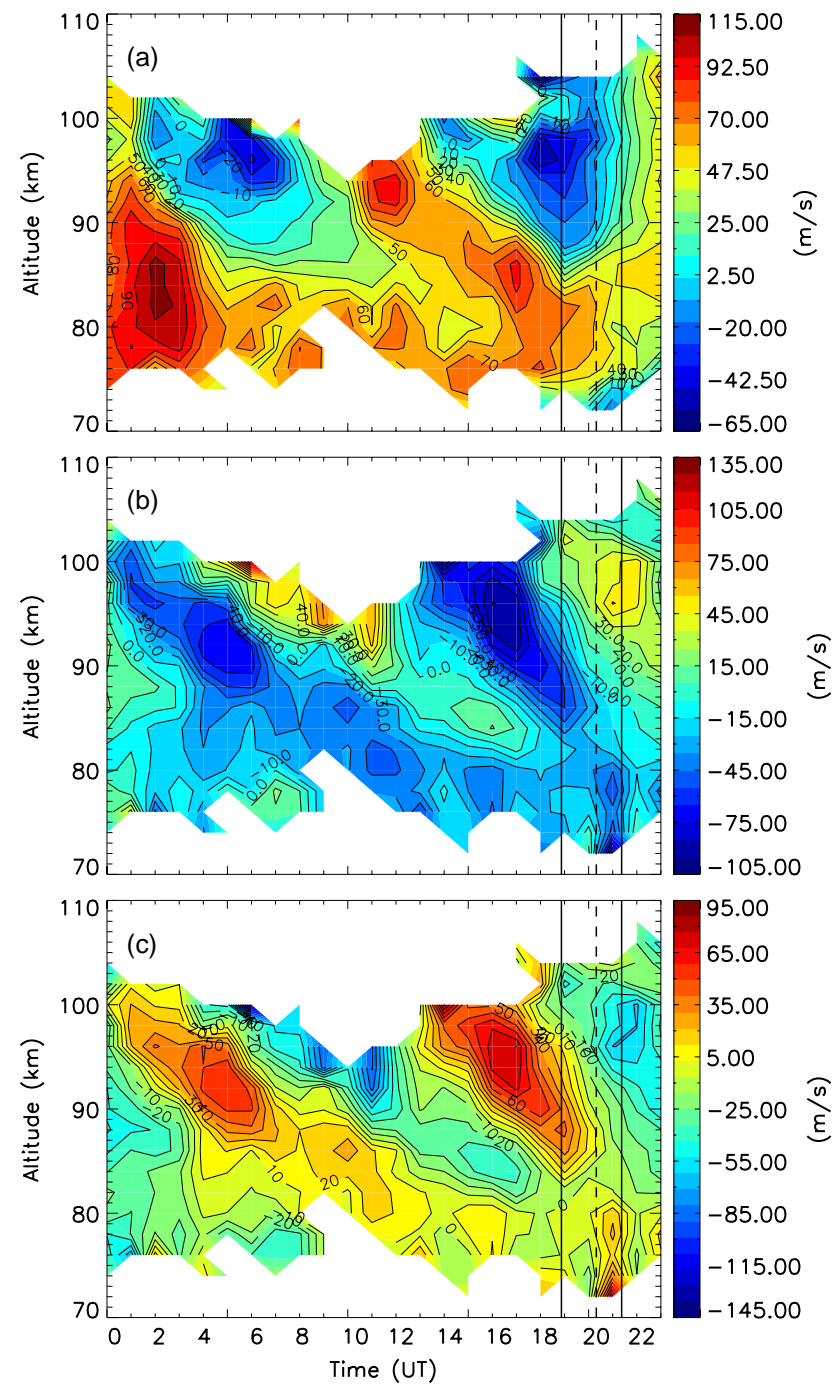

Fig. 6. Contour plot of (a) hourly zonal wind, (b) meridional wind, and (c) background wind in the wave propagation direction measured by the meteor radar on the night of 8-9 January 2011. The vertical solid lines indicate the time when the bore was observed. The vertical dashed line indicates the time when the leading edge of the bore passed through the zenith of the airglow observation.

ited a reversal when the leading front passed over the ASAI (the time indicated by the vertical dashed lines in Fig. 6c). The average wind speed in the bore propagation direction (about $10 \mathrm{~m} \mathrm{~s}^{-1}$ ) is much smaller than the observed phase speed of the bore event (about $68 \mathrm{~m} \mathrm{~s}^{-1}$ ). Thus, the bore cannot be filtered out. Similar results have been reported by other imager observations (e.g., Taylor et al., 1995; Smith et al., 2003; She et al., 2004; Narayanan et al., 2009; Bageston et al., 2011b). Bageston et al. (2011b) found that small winds in the wave propagation direction do not have influence on the duct configuration, emphasizing the thermal duct. Figure $6 \mathrm{c}$ shows a strong background wind shear, which increases from $0 \mathrm{~m} \mathrm{~s}^{-1}$ at $82 \mathrm{~km}$ to $60 \mathrm{~m} \mathrm{~s}^{-1}$ at $87 \mathrm{~km}$ along the direction 


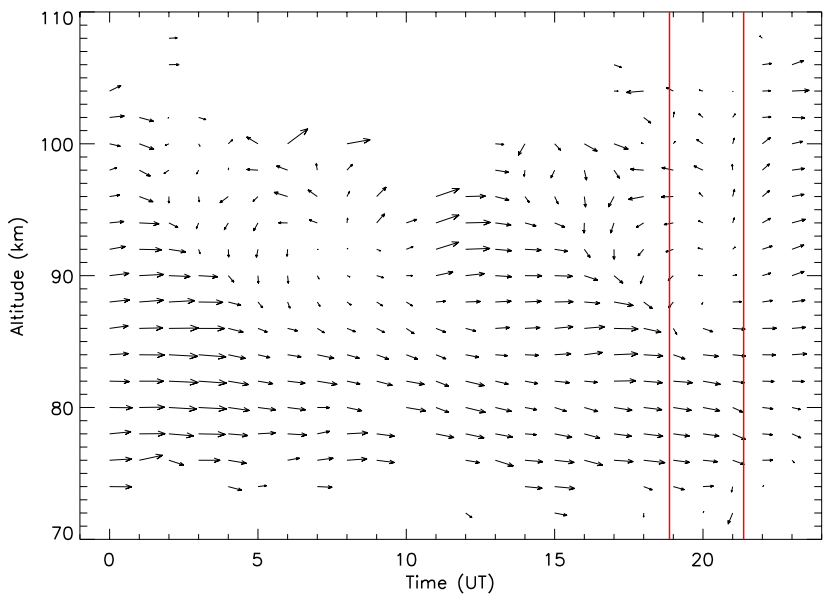

Fig. 7. The vector wind field measured by the meteor radar on the night of 8-9 January 2011. The magnitude and direction of the vector wind is denoted by the arrow length and arrow direction (upward is north, right is east), respectively. The solid lines enclose the time when the bore was observed.
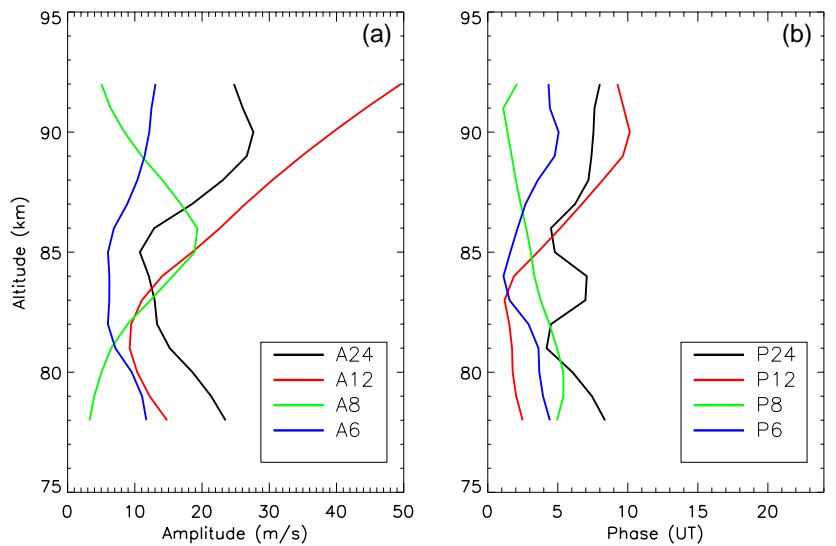

Fig. 8. The average diurnal, semidiurnal, terdiurnal, and $6 \mathrm{~h}$ tidal wind components in the bore propagation direction from 19:00 UT to 21:00 UT on the night of 8-9 January 2011: (a) amplitude $\left(\mathrm{m} \mathrm{s}^{-1}\right)$; (b) phase (UT).

of bore propagation around 19:00 UT. The vector wind field, obtained from the zonal and meridional winds (see Fig. 6a and b), is shown in Fig. 7. At 19:00-20:00 UT, the vector wind direction from 80 to $84 \mathrm{~km}$ is almost east, with an average speed of $70 \mathrm{~m} \mathrm{~s}^{-1}$. However, above $86 \mathrm{~km}$, the wind undergoes a reversal, from east to the west. The average wind from 86 to $90 \mathrm{~km}$ is relatively small (about $22 \mathrm{~m} \mathrm{~s}^{-1}$ ). This height is also consistent with the ducting range in Fig. 5c. The wind shear around $86 \mathrm{~km}$ may be important for the propagation environment of the bore, along with the temperature inversion layer.

Aside from the winds shear, tidal winds can contribute to Doppler ducts (Bageston et al., 2011a). In order to extract the tidal components from the observed wind, harmonic fit-

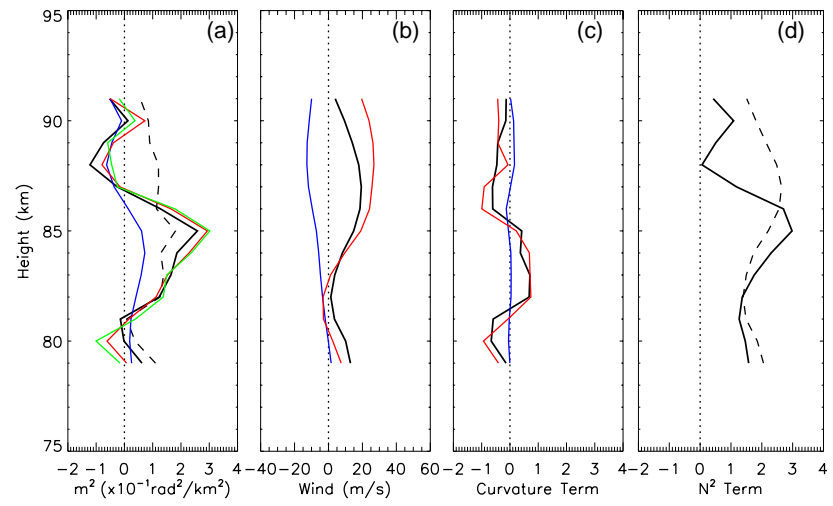

Fig. 9. (a) Vertical wavenumber $m^{2}$ under different wind profiles in (b), tide wind without $6 \mathrm{~h}$ tidal wind (green line), and constant buoyancy frequency squared $\left(N^{2}=0.0004 \mathrm{rad}^{2} \mathrm{~km}^{-2}\right)$ (dashed line). (b) Observed wind (black), mean wind (blue), and tide wind (mean wind $+24 h+12 h+8 h+6 h$ tidal winds) (red) in the wave propagation direction from 19:00 UT to 21:00 UT. (c) The second term in Eq. (2) under different wind profiles in (b). (d) The buoyancy frequency term (the first term in Eq. 1) corresponding to the solid black and dashed lines in (a).

ting has been applied to the observed wind. The harmonic equation can be expressed as

$V=V_{0}+\sum_{i} V_{i} \cos \left[\left(\frac{2 \pi}{T_{i}}\right)\left(t-\phi_{i}\right)\right]$,

where $V$ represents the observed wind, $V_{0}$ represents the mean wind, $i$ is index of tidal component, $V_{i}$ is the amplitude, $\phi_{i}$ is the phase, $T_{i}$ is the period of the tide, and $t$ is the time. We only consider the $24,12,8$, and $6 \mathrm{~h}$ tidal components. Figure 8 presents the average tidal components in the wave propagation direction from 19:00 UT to 21:00 UT on the night of 8-9 January 2011. The average amplitudes of $24,12,8$, and $6 \mathrm{~h}$ tidal components in the duct region (from $81 \mathrm{~km}$ to $87 \mathrm{~km}$ ) are $12 \mathrm{~m} \mathrm{~s}^{-1}, 16 \mathrm{~m} \mathrm{~s}^{-1}, 15 \mathrm{~m} \mathrm{~s}^{-1}$, and $7 \mathrm{~m} \mathrm{~s}^{-1}$, respectively. We can see that the amplitude of the semidiurnal tide grows rapidly from 82 to $92 \mathrm{~km}$ (the red line in Fig. 8a).

Using the same methodology employed by Bageston et al. (2011a, b), the mean wind and the tidal winds were combined to create a new wind profile along the bore propagation direction. Under different wind field conditions (observed wind, mean wind, mean wind and tidal winds), we are able to evaluate how the tidal winds contribute to the duct for the bore propagation. Figure 9 displays the $m^{2}$ profiles, wind profiles in the wave propagation direction, curvature terms and the buoyancy frequency terms, respectively. Figure 9a presents the $m^{2}$ profiles under different wind field conditions in Fig. 9b. The lower boundary of the duct disappears when the tidal winds $(24 h+12 h+8 h+6 h$ tidal winds) were removed from the observed wind (see blue line in Fig. 9a). Also, without considering the $6 \mathrm{~h}$ tidal component 
(mean wind $+24 \mathrm{~h}+12 \mathrm{~h}+8 \mathrm{~h}$ tidal winds), the $m^{2}$ profile is shown in Fig. 9a (see green line). We can see that the two profiles are almost identical (the blue and green lines in Fig. 9a). Thus, the $6 \mathrm{~h}$ tidal wind has little influence on the duct formation, which is consistent with the smaller amplitude of the $6 \mathrm{~h}$ tidal wind shown in Fig. 8a (see blue line). The winds contributing to the $m^{2}$ profiles are mainly controlled by the diurnal, semidiurnal and terdiurnal tidal components because the average amplitudes of $24 \mathrm{~h}, 12 \mathrm{~h}, 8 \mathrm{~h}$ tidal components are almost equal in the duct region (from $81 \mathrm{~km}$ to $87 \mathrm{~km}$ ). Assuming the squared buoyancy frequency does not show variation in the vertical height as discussed by Bageston et al. (2011a), the $m^{2}$ profile under the condition of constant buoyancy frequency $\left(N^{2}=0.0004 \mathrm{rad}^{2} \mathrm{~km}^{-2}\right)$ is also shown in Fig. 9a (see dashed line). It is noted that both the upper and lower boundary of the duct disappeared. Also, a comparison of the $\mathrm{m}^{2}$ profile generated from observed wind (see black line) indicates that the $m^{2}$ profiles described above (blue and dashed lines) underwent drastic change. Furthermore, both the curvature term (see the black line in Fig. 9c) and the buoyancy frequency term (see the black line in Fig. 9d) play important roles in constructing the $m^{2}$ profile (black line in Fig. 9a). Therefore, we conclude that both the temperature and the tidal winds ( $24 \mathrm{~h}, 12 \mathrm{~h}, 8 \mathrm{~h}$ tidal winds) are significant in the duct formation.

\subsection{The bore parameters}

The normalized bore strength $\beta$ (Lighthill, 1978) can be given by

$\beta=\left(h_{1}-h_{0}\right) / h_{0}$,

where $h_{0}$ and $h_{1}$ are the depth or thickness of the duct channel before and after the bore passage, respectively. For channel bores, if $\beta<0.3$, then the phase-locked trailing wavefronts behind the bore are stable and the disturbance is called an undular bore. When $\beta>0.3$, the bore becomes unstable, resulting in the generation of turbulence. Such a disturbance is called a turbulent or foaming bore. In this observation, because no turbulence is observed behind the bore front, $\beta$ must be less than 0.3 . To investigate this mesospheric bore, we adopt the model developed by Dewan and Picard (1998). The model is based on hydraulic jump theory. According to the model, the propagation speed $\left(u_{0}\right)$, the horizontal wavelength $\left(\lambda_{\mathrm{h}}\right)$ and the bore amplitude $(a)$ are expressed as

$$
\begin{aligned}
& u_{0}=\sqrt{g^{\prime} \frac{h_{1}\left(h_{1}+h_{0}\right)}{2 h_{0}},} \\
& \lambda_{\mathrm{h}}=\frac{2 \pi h_{1}}{3} \sqrt{\frac{2 h_{0}}{h_{1}-h_{0}},} \\
& a=\frac{1}{\sqrt{3}} \frac{h_{1}\left(h_{1}-h_{0}\right)}{h_{0}},
\end{aligned}
$$

in which $g^{\prime}=g[(\Delta \theta) / \bar{\theta}]$ is the buoyant acceleration due to gravity, where $\bar{\theta}=T\left(P_{0} / P\right)^{0.288}$ is the potential temperature. Here, $T$ is the temperature, $P$ is the pressure, $P_{0}$ is the reference pressure of $1000 \mathrm{mb}, \bar{\theta}$ is the mean potential temperature at the bore altitude, and $\Delta \theta$ is the change in potential temperature from $h_{0}$ to $h_{1}$. The temperature and pressure data were obtained from SABER. Using the method described in detail by Dewan and Picard (1998), $g^{\prime}$ was calculated to be $1.08 \mathrm{~m} \mathrm{~s}^{-2}$. For an undular bore, like the one in this study, we set the value of $\beta$ as $0.1,0.2$ and 0.3. The half width of the duct can be determined from $N^{2}$ profile in Fig. $5 \mathrm{c}$, giving $h_{0}=3 \mathrm{~km}$. Using Eq. (4), we get $h_{1}=3.3 \mathrm{~km}$, $3.6 \mathrm{~km}$ and $3.9 \mathrm{~km}$, respectively. Using Eqs. (5) and (6), we obtain $u_{0}=61 \mathrm{~m} \mathrm{~s}^{-1}, 65 \mathrm{~m} \mathrm{~s}^{-1}, 70 \mathrm{~m} \mathrm{~s}^{-1}$ and $\lambda_{\mathrm{h}}=31 \mathrm{~km}$, $24 \mathrm{~km}, 21 \mathrm{~km}$, respectively. The results coincide well with the phase velocity of $68 \mathrm{~m} \mathrm{~s}^{-1}$ and horizontal wavelength of $22 \mathrm{~km}$ when the value of $\beta$ is 0.3 . The amplitude of the bore is calculated to be $0.68 \mathrm{~km}$ (assuming $\beta=0.3$ ) from Eq. (7).

The bore dissipates its energy through the generation of trailing wave crests (Lighthill, 1978). Dewan and Picard (1998) estimated the rate of adding wave crests to the back of the wave train as

$$
\frac{\mathrm{d} W}{\mathrm{~d} t}=\frac{U\left(h_{1}-h_{0}\right)^{3}}{2 a^{2} \lambda_{\mathrm{h}} h_{1}}\left(\mathrm{~h}^{-1}\right)
$$

For the reported bore event here, the increment rate of wave crests is $2.43 \mathrm{~h}^{-1}$ (assuming $\beta=0.3$ ). However, this parameter is not easy to verify in this study, because the crests behind the leading front of the bore become unclear after 20:30 UT. In addition, the newly formed crests cannot be detected from airglow observations if they are not strong enough to perturb the airglow layer (Narayanan et al., 2009). She et al. (2004) suggested that the disappearing rate of wave crests associated with instability should also be considered. To understand the generation and disappearing rate of the bore wave trains, the energy dissipation of the bore should be addressed in a future study. A long-lived and stable bore event, such as the one reported by Smith et al. (2003), is necessary to verify the increment rate of wave crests predicted by Dewan and Picard (1998). The bore event in this study is too transient.

\subsection{The possible effects of the bore on the Na density}

Simultaneous Na density lidar measurements were conducted at Yanqing $\left(40.4^{\circ} \mathrm{N}, 116.0^{\circ} \mathrm{E}\right)$ during the bore event. Figure 10 shows the simultaneous $\mathrm{Na}$ density in the height range of $75-105 \mathrm{~km}$. The dashed line at 20:21 UT indicates the time when the leading bore front passed through the zenith of the lidar. It is noted that from 17:00 UT to 20:00 UT, the peak of the sodium layer was located at its normal height $\sim 88 \mathrm{~km}$. Following the passage of the bore front over the $\mathrm{Na}$ lidar (the vertical dashed line in Fig. 10), the sodium density peak shifted downward dramatically. It was displaced about $4 \mathrm{~km}$ downwards and was centered around $84 \mathrm{~km}$ between 20:21 UT and 21:40 UT. After the passage of the bore, the 


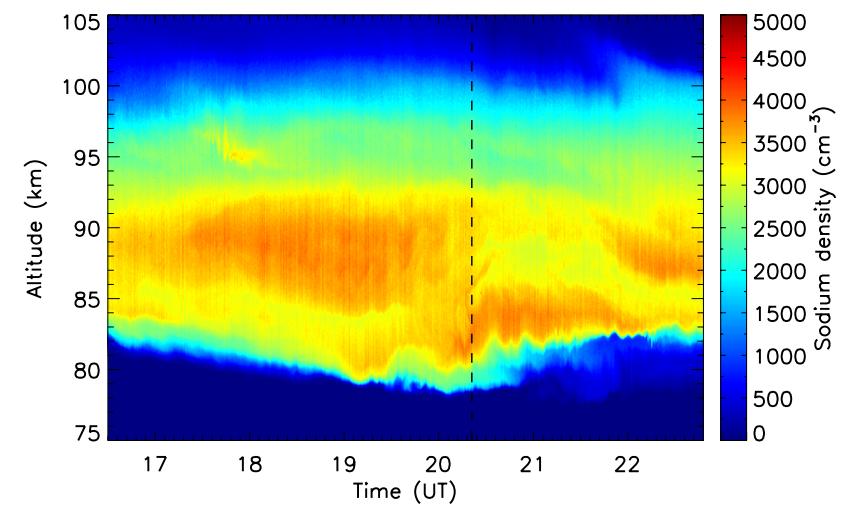

Fig. 10. Sodium density on the night of 8-9 January 2011. The vertical dashed line indicates 20:21 UT when the leading edge of the bore passed through the zenith of the $\mathrm{Na}$ lidar.

peak of the sodium density shifted upward again to around $87.5 \mathrm{~km}$ at 21:40 UT. Medeiros et al. (2001) and Smith et al. (2005) have studied the variations of sodium density during bore events. The variation of the sodium density is continuous in their sodium density maps. Moreover, the peaks of the sodium density observations show downward phase propagations during these bore events (see Fig. 6 in Medeiros et al., 2001, and Fig. 3 in Smith et al., 2005). They suggested that the downward shift of the sodium density peak might be due to the large-scale gravity waves with downward phase propagation. In contrast, the peak of the sodium density shifted downward disruptively in the bore event observed in this study. Also, there is no evidence that the bore event was associated with a large vertically propagating gravity wave.

The vertical displacement of the Na layer may be induced by the mesospheric bore as suggested by Yue et al. (2009). At the front of the bore, the atmosphere is approaching convective instability with overturning (vertical phase of potential temperature) (Seyler, 2005; Yue et al., 2009). The strong turbulence induced by the front can cause strong vertical transport (Gardner and Liu, 2010). Based on the calculations and analysis in Sect. 3.3, a reasonable value for the bore strength $\beta$ is about 0.3 , which is the threshold between undular bore and turbulent bore conditions. Thus, the abrupt downward shift of the peak of the sodium layer may be due to the bore event.

In addition, Xu et al. (2006) used numerical simulations and lidar observations to examine the perturbations in the sodium layer caused by an overturning gravity wave in the mesopause region. They proposed that the sodium density perturbation exhibits a more pronounced overturning behavior at the bottomside of the Na layer than the topside of the layer. Therefore, we speculate that the bore event has an essential role in the abrupt downward shift of the peak of the sodium layer. However, the details of how the bore modulates the sodium density are still unknown and will be investigated in the future.

\section{Discussions and conclusions}

In this work, we report a mesospheric bore event on the night of 8-9 January 2011 observed by the ASAI located at Xinglong $\left(40.2^{\circ} \mathrm{N}, 117.4^{\circ} \mathrm{E}\right)$, China. As far as we know, this is the first report of a mesospheric bore over China. The bore propagated from northeast to southwest with a horizontal wavelength of $22 \mathrm{~km}$ and an average phase velocity of $68 \mathrm{~m} \mathrm{~s}^{-1}$. Taylor et al. (1995) reported a bore event with similar parameters, having a horizontal wavelength of $19.3 \mathrm{~km}$, and an apparent phase speed of $76 \mathrm{~m} \mathrm{~s}^{-1}$. Others have reported bore events with longer wavelengths. For example, Nielsen et al. (2006) and Fechine et al. (2009) presented bore events with horizontal wavelengths of $30 \mathrm{~km}$ and $42.4 \mathrm{~km}$, respectively. Bageston et al. (2011a) reported a mesospheric front with a horizontal wavelength of $33 \mathrm{~km}$. The longer horizontal wavelengths may be influenced by different atmospheric conditions. The horizontal wavelength and the propagation speed of the bore are consistent with the results predicted by Dewan and Picard (1998).

By analyzing duct configurations with different temperatures and wind fields, we found that both the wind and temperature play an essential role in the formation of ducts where mesospheric bores propagate. The average wind along the propagation direction of the bore was weak at the $\mathrm{OH}$ emission height when the bore was observed. However, there was a strong wind shear in the height range of $82-87 \mathrm{~km}$. The strong wind shear may also play an important role in the propagation of the bore event.

Simultaneous Na density measurements show a downward shift of the peak of $\mathrm{Na}$ density during the passage of the mesospheric front event. The analysis suggests that the bore event has a strong impact on the abrupt downward shift of the peak of the sodium density. Until now, there has been no theoretical work to study the evolution of the sodium layer in the presence of a mesospheric bore. To understand how the mesospheric bore modulates the sodium density, model simulations are required in a future work.

Simultaneous temperature data near the bore observation site were not available. Therefore, a caveat that the temperature data from the TIMED/SABER is $6 \mathrm{~h}$ prior to the mesospheric bore event must accompany the analysis. In this study, the temperature inversion layer occurred from 80 to $86 \mathrm{~km}$ in winter (January) nighttime. This presents some limitations to the present work. Even with such a limitation, credible evidence (States and Gardner, 2000a, b; Sica et al., 2002; Leblanc et al., 1995; Leblanc and Hauchecorne, 1997) that the mesospheric inversion layer (MIL) can persist longer than $6 \mathrm{~h}$ and cover a region greater than $400 \mathrm{~km} \times 400 \mathrm{~km}$ can be found. Using a sodium wind/temperature lidar, States and Gardner (2000a) investigated the seasonal variations of the 
temperature structure in mesopause region at Urbana, Illinois $\left(40^{\circ} \mathrm{N}, 88^{\circ} \mathrm{W}\right)$, which is at the same latitude as Xinglong $\left(40.2^{\circ} \mathrm{N}, 117.4^{\circ} \mathrm{E}\right)$. They found that there existed a weak temperature inversion layer around $90 \mathrm{~km}$ in both annual and mean February nighttime temperatures. Using ISAMS instrument on board the UARS satellite, Leblanc et al. (1995) showed that the MIL spanned from $10^{5}$ to $10^{6} \mathrm{~km}^{2}$ during December 1991 at mid-latitudes between 70 and $80 \mathrm{~km}$. Furthermore, Sica et al. (2002) reported that the MIL may persist over $10 \mathrm{~h}$. Using Rayleigh lidars located in Observatoire Haute Provence ( $\left.44^{\circ} \mathrm{N}, 5^{\circ} \mathrm{E}\right)$, Leblanc et al. (1995) and Leblanc and Hauchecorne (1997) also presented a temperature inversion layer from $81 \mathrm{~km}$ to $84 \mathrm{~km}$ on the nights of 11/12 December 1991 (see Fig. 2 in Leblanc et al., 1995, and Fig. 2 in Leblanc and Hauchecorne, 1997). The height range of the temperature inversion layer shows a good agreement with the temperature profiles derived from SABER in this paper (see Fig. 4a). In order to better understand the characteristics of the mesospheric bores, future studies will be need to obtain the simultaneous temperature measurements.

Acknowledgements. This work was supported by the Chinese Academy of Sciences (KZZD-EW-01-2), the National Science Foundation of China (41229001, 41074109, 41274153, 41004063) and the National Important basic Research Project of China (2011CB811405). This project is also supported by the Specialized Research Fund for State Key Laboratories. We acknowledge the use of data from the Chinese Meridian Project. We also thank the TIMED/SABER team for providing the data used in this paper. We are grateful to R. A. Vincent for the great help in discussing the measurement uncertainty of meteor radar and thank E. E. Remsberg for the help with the estimations of SABER temperature profile uncertainty.

Topical Editor C. Jacobi thanks J. V. Bageston and one anonymous referee for their help in evaluating this paper.

\section{References}

Bageston, J. V., Wrasse, C. M., Batista, P. P., Hibbins, R. E., Fritts, D. C., Gobbi, D., and Andrioli, V. F.: Observation of a mesospheric front in a thermal-doppler duct over King George Island, Antarctica, Atmos. Chem. Phys., 11, 12137-12147, doi:10.5194/acp-11-12137-2011, 2011a.

Bageston, J. V., Wrasse, C. M., Hibbins, R. E., Batista, P. P., Gobbi, D., Takahashi, H., Fritts, D. C., Andrioli, V. F., Fechine, J., and Denardini, C. M.: Case study of a mesospheric wall event over Ferraz station, Antarctica (62 $\left.{ }^{\circ} \mathrm{S}\right)$, Ann. Geophys., 29, 209-219, doi:10.5194/angeo-29-209-2011, 2011 b.

Brown, L. B., Gerrard, A. J., Meriwether, J. W., and Makela, J. J.: All sky imaging observations of mesospheric fronts in OI $557.7 \mathrm{~nm}$ and broadband $\mathrm{OH}$ airglow emissions: Analysis of frontal structure, atmospheric background conditions, and potential sourcing mechanisms, J. Geophys. Res., 109, D19104, doi:10.1029/2003JD004223, 2004.

Chimonas, G. and Hines, C. O.: Doppler Ducting of Atmospheric Gravity-Waves, J. Geophys. Res., 91, 1219-1230, 1986.
Dewan, E. M. and Picard, R. H.: Mesospheric bores, J. Geophys. Res., 103, 6295-6306, 1998.

Dewan, E. M. and Picard, R. H.: On the origin of mesospheric bores, J. Geophys. Res., 106, 2921-2928, 2001.

Fechine, J., Wrasse, C. M., Takahashi, H., Medeiros, A. F., Batista, P. P., Clemesha, B. R., Lima, L. M., Fritts, D. C., Laughman, B., Taylor, M. J., Pautet, P. D., Mlynczak, M. G., and Russell, J. M.: First observation of an undular mesospheric bore in a Doppler duct, Ann. Geophys., 27, 1399-1406, doi:10.5194/angeo-271399-2009, 2009.

Garcia-Comas, M., Lopez-Puertas, M., Marshall, B. T., Wintersteiner, P. P., Funke, B., Bermejo-Pantaleon, D., Mertens, C. J., Remsberg, E. E., Gordley, L. L., Mlynczak, M. G., and Russell III, J. M.: Errors in Sounding of the Atmosphere using Broadband Emission Radiometry (SABER) kinetic temperature caused by non-local-thermodynamic-equilibrium model parameters, J. Geophys. Res., 113, D24106, doi:10.1029/2008JD010105, 2008.

Gardner, C. S. and Liu, A. Z.: Wave-induced transport of atmospheric constituents and its effect on the mesospheric Na layer, J. Geophys. Res., 115, D20302, doi::10.1029/2010JD014140, 2010.

Holdsworth, D. A., Reid, I. M., and Cervera, M. A.: Buckland Park all-sky interferometric meteor radar, Radio Sci., 39, RS5009, doi:10.1029/2003RS003014, 2004.

Isler, J. R., Taylor, M. J., and Fritts, D. C.: Observational evidence of wave ducting and evanescence in the mesosphere, J. Geophys. Res., 102, 26301-26313, doi:10.1029/97JD01783, 1997.

Laughman, B., Fritts, D. C., and Werne, J.: Numerical simulation of bore generation and morphology in thermal and Doppler ducts, Ann. Geophys., 27, 511-523, doi:10.5194/angeo-27-511-2009, 2009.

Leblanc, T. and Hauchecorne, A.: Recent observations of mesospheric temperature inversions, J. Geophys. Res., 102, 19471$19482,1997$.

Leblanc, T., Hauchecorne, A., Chanin, M., Rodgers, C., Taylor, F., and Livesey, N.: Mesospheric temperature inversions as seen by ISAMS in December 1991, Geophys. Res. Lett., 22, 1485-1488, doi:10.1029/94GL03274, 1995.

Li, Q., Xu, J., Yue, J., Yuan, W., and Liu, X.: Statistical characteristics of gravity wave activities observed by an $\mathrm{OH}$ airglow imager at Xinglong, in northern China, Ann. Geophys., 29, 1401-1410, doi:10.5194/angeo-29-1401-2011, 2011.

Lighthill, J.: Waves in Fluids, Cambridge Univ. Press, New York, 1978.

Medeiros, A. F., Taylor, M. J., Takahashi, H., Batsista, P. P., and Gobbi, D.: An unusual airglow wave event observed at Cachoeira Paulista $23^{\circ}$ S, Adv. Space Res., 27, 1749-1754, 2001.

Medeiros, A. F., Fechine, J., Buriti, R. A., Takahashi, H., Wrasse, C. M., and Gobbi, D.: Response of $\mathrm{OH}, \mathrm{O}_{2}$, and OI 5577 airglow emissions to the mesospheric bore in the equatorial region of Brazil, Adv. Space Res., 35, 1971-1975, 2005.

Mertens, C. J.: Retrieval of mesospheric and lower thermospheric kinetic temperature from measurements of $\mathrm{CO}_{2} 15 \mu \mathrm{m}$ earth limb emission under non-LTE conditions, Geophys. Res. Lett., 28, 1391-1394, 2001.

Narayanan, V. L., Gurubaran, S., and Emperumal, K.: A case studyof a mesospheric bore event observed with an all-sky airglow imagerat Tirunelveli $\left(8.7^{\circ} \mathrm{N}\right)$, J. Geophys. Res., 114, D08114, doi:10.1029/2008JD010602, 2009. 
Nielsen, K., Taylor, M. J., Stockwell, R. G., and Jarvis, M. J.: Anunusual mesospheric bore event observed at high latitudes over Antarctica, Geophys. Res. Lett., 33, L07803, doi:10.1029/2005GL025649, 2006.

Remsberg, E. E., Marshall, B. T., Garcia-Comas, M., Krueger, D., Lingenfelser, G. S., Martin-Torres, J., Mlynczak, M. G., Russell III, J. M., Smith, A. K., Zhao, Y., Brown, C., Gordley, L. L., Lopez-Gonzalez, M. J., Lopez-Puertas, M., She, C.-Y., Taylor, M. J., and Thompson, R. E.: Assessment of the quality of the Version 1.07 temperature-versus-pressure profiles of the middle atmosphere from TIMED/SABER, J. Geophys. Res., 113, D17101, doi:10.1029/2008JD010013, 2008.

Seyler, C. E.: Internal waves and undular bores in mesospheric inversion layers, J. Geophys. Res., 110, D09S05, doi:10.1029/2004JD004685, 2005.

She, C.-Y., Li, T., Williams, B. P., Yuan, T., and Picard, R. H.: Concurrent $\mathrm{OH}$ imager and sodium temperature/wind lidar observationof a mesopause region undular bore event over Fort Collins/Platteville, Colorado, J. Geophys. Res., 109, 2210722115, 2004.

Sica, R. J., Thayaparan, T., Argall, P. S., Russell, A. T., and Hocking, W. K.: Modulation of upper mesospheric temperature inversions due to tidal-gravity wave interactions, J. Atmos. Terr. Phys., 64, 915-922, 2002.

Smith, S. M., Taylor, M. J., Swenson, G. R., She, C.-Y., Hocking, W., Baumgardner, J., and Mendillo, M.: A multidiagnostic investigation of the mesospheric bore phenomenon, J. Geophys. Res., 108, 1083, doi:10.1029/2002JA009500, 2003.

Smith, S. M., Friedman, J., Raizada, S., Tepley, C., Baumgardner, J., and Mendillo, M.: Evidence of mesospheric bore formation from abreaking gravity wave event: Simultaneous imaging and lidar measurements, J. Atmos. Sol-Terr. Phy., 67, 345-356, 2005.

Smith, S. M., Scheer, J., Reisin, E. R., Baumgardner, J., and Mendillo, M.: Characterization of exceptionally strong mesospheric wave events using all-sky and zenith airglow observations, J. Geophys. Res., 111, A09309, doi:10.1029/2005JA011197, 2006.

States, R. J. and Gardner, C. S.: Thermal structure of themesopause region (80-105) at $40^{\circ} \mathrm{N}$ latitude. Part 1: Seasonal variations, J. Atmos. Sci., 57, 66-77, 2000a.
States, R. J. and Gardner, C. S.: Thermal structure of the mesopauseregion (80-105 km) at $40^{\circ} \mathrm{N}$ latitude. Part II: Diurnal variations, J. Atmos. Sci., 57, 78-92, 2000b.

Stockwell, R. G., Taylor, M. J., Nielson, K., and Jarvis, M. J.: A novel joint space-wave number analysis of an unusual Antarctic gravity wave event, Geophys. Res. Lett., 33, L08805, doi:10.1029/2005GL025660, 2006.

Stockwell, R. G., Taylor, M. J., Nielson, K., and Jarvis, M. J.: The evolution of a breaking mesospheric bore wave packet, J. Geophys. Res., 116, D19102, doi:10.1029/2010JD015321, 2011.

Taylor, M. J., Turnbull, D. N., and Lowe, R. P.: Spectrometric and imaging measurements of a spectacular gravity wave event observed during the ALOHA-93 campaign, Geophys. Res. Lett., 20, 2849-2852, 1995.

Vincent, R. A., Kovalam, S., Reid, I. M., and Younger, J. P.: Gravity wave flux retrievals using meteor radars, Geophys. Res. Lett. , 37, L14802, doi:10.1029/2010GL044086, 2010.

Wang, J., Yang, Y., Cheng, X., Yang, G., Song, S., and Gong, S.: Double sodium layers observation over Beijing, China, Geophys. Res. Lett., 39, L15801, doi:10.1029/2012GL052134, 2012.

Xu, J., Smith, A. K., Collins, R. L., and She, C.-Y.: Signature of an overturning gravity wave in the mesospheric sodium layer: Comparison of a nonlinear photochemical-dynamical model and lidar observations, J. Geophys. Res., 111, D17301, doi:10.1029/2005JD006749, 2006.

Yu, Y., Wan, W., Ning, B., Liu, L., Wang, Z., Hu, L., and Ren, Z.: Tidal Wind Mapping from observations of a meteor radar chain in December, 2011, J. Geophys. Res., in press, doi:10.1029/2012JA017976, 2013.

Yue, J., She, C.-Y., Nakamura, T., Harrell, S., and Yuan, T.: Mesospheric bore formation from large-scale gravity wave perturbations observed by collocated all-sky $\mathrm{OH}$ imager and sodium lidar, J. Atmos. Sol-Terr. Phys., 72, 7-18, doi:10.1016/j.jastp.2009.10.002, 2009.

Yue, J., She, C.-Y., and Liu, H.-L.: Large wind shears and stabilities in the mesopause region observed by $\mathrm{Na}$ windtemperature lidar at midlatitude, J. Geophys. Res., 115, A10307, doi:10.1029/2009JA014864, 2010.

Zhang, F.: Generation of mesoscale gravity waves in uppertropospheric jet-front systems, J. Atmos. Sci., 61, 440-457, 2004. 